\title{
Location, Location, Location: The Role of Objective Neighborhood Characteristics for Perceptions of Control
}

\author{
Johanna Drewelies $^{\mathrm{a}}$ Peter Eibich $^{\mathrm{b}}$ Sandra Düzel ${ }^{\mathrm{c}}$ Simone Kühn ${ }^{\mathrm{c}}$ \\ Christian Krekel $^{d}$ Jan Goebel ${ }^{e}$ Jens Kolbe ${ }^{f}$ Ilja Demuth ${ }^{9}$ \\ Ulman Lindenberger ${ }^{c, h}$ Gert G. Wagner ${ }^{c, e}$ Denis Gerstorf ${ }^{a}, \mathrm{e}, \mathrm{i}$
}

\begin{abstract}
aDepartment for Psychology, Humboldt University Berlin, Berlin, Germany; ${ }^{b}$ Max Planck Institute for Demographic Research, Rostock, Germany; ${ }^{C}$ Max Planck Institute for Human Development, Berlin, Germany; ${ }^{\text {dDepartment of }}$ Psychological and Behavioural Science, London School of Economics, London, UK; ${ }^{\circ}$ German Institute for Economic Research, Berlin, Germany; ${ }^{f}$ Institute of Economics and Law, Technical University, Berlin, Germany; ${ }^{9}$ Charité -

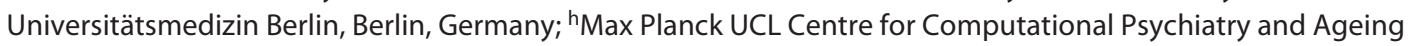
Research, Berlin, Germany, and London, UK; 'Department of Human Development and Family Studies, Pennsylvania State University, University Park, University Park, PA, USA
\end{abstract}

\section{Keywords}

Aging $\cdot$ Control beliefs $\cdot$ Geocoding $\cdot$ Neighborhood amenities · Green spaces · Berlin Aging Study II

\begin{abstract}
Introduction: Control beliefs can protect against age-related declines in functioning. It is unclear whether neighborhood characteristics shape how much control people perceive over their life. This article studies associations of neighborhood characteristics with control beliefs of residents of a diverse metropolitan area (Berlin, Germany). Methods: We combine self-report data about perceptions of control obtained from participants in the Berlin Aging Study II ( $N=507$, 60-87 years, 51\% women) with multisource geo-referenced indicators of neighborhood characteristics using linear regression models. Results: Findings indicate that objective neighborhood characteristics (i.e., unemployment rate) are indeed tied to perceptions of control, in particular, how much control participants feel others have over their lives. Including neighborhood characteristics in part doubled the
\end{abstract}

karger@karger.com www.karger.com/ger

Karger $\stackrel{\text { ' }}{5}$

BOPEN ACCESS
(C) 2021 The Author(s)

Published by S. Karger AG, Basel

This is an Open Access article licensed under the Creative Commons Attribution-NonCommercial-4.0 International License (CC BY-NC) (http://www.karger.com/Services/OpenAccessLicense), applicable to the online version of the article only. Usage and distribution for commercial purposes requires written permission. amount of explained variance compared with a reference model covarying for demographic characteristics only (from $R^{2}=0.017$ to $R^{2}=0.030$ for internal control beliefs; $R^{2}=0.056$ to $R^{2}=0.102$ for external control beliefs in chance; $R^{2}=0.006$ to $R^{2}=0.030$ for external control beliefs in powerful others). Discussion/Conclusion: Findings highlight the importance of access to neighborhood resources for control beliefs across old age and can inform interventions to build up neighborhood characteristics which might be especially helpful in residential areas with high unemployment.

(c) 2021 The Author(s)
Published by S. Karger AG, Basel

\section{Introduction}

Location counts not only in real estate. Neighborhoods shape many aspects of their residents' lives, such as health or well-being [1]. Location also touches on many

Johanna Drewelies and Peter Eibich: joint first authors.
Correspondence to:

Johanna Drewelies, johanna.drewelies@hu-berlin.de

Peter Eibich, eibich@ demogr.mpg.de 
aspects that have been shown to affect psychosocial functioning. In this study, we aimed to investigate the role of neighborhood characteristics in control beliefs. Control beliefs can be defined as an individual's perception about their ability to shape their life circumstances and to attain desired outcomes [2]. Lifespan psychology considers control beliefs to be multi-dimensional, including facets of internal and external control (for an overview, see [3]).

Internal control beliefs reflect beliefs about one's capacity to bring about a given outcome [4]. They refer to desirable and undesirable outcomes such as fulfilling the tasks of everyday life or perceptions of personal responsibility, such as motivation to invest more diligence in the future. In contrast, external control beliefs are beliefs about forces that are beyond one's control. External control beliefs often denote powerful others in one's personal, social, or professional life (e.g., spouse or caregiver) who determine important aspects of life or refer to the belief that good or bad things in life are determined by chance, fate, or luck [5].

Lifespan theory emphasizes that control beliefs are an integral component of adaptive self-regulation and a key predictor of successful development and aging $[6,7]$. In particular, perceiving more control over one's life is linked to better health and overall lower mortality. These effects remain while accounting for other psychosocial resources, such as well-being, personality, or social integration, indicating that perceptions of control have predictive validity for aging related outcomes over and above other factors $[8,9]$. It is thus crucial to understand correlates of control beliefs. Studies have shown that control beliefs are associated with individual difference characteristics such as socio-demographic, physical health, cognitive, and social factors (e.g., [7]). Yet, individual development does not occur in isolation [10]. Empirical studies have shown that the contexts individuals live in, including features of the neighborhood environment, matter for individual physical and psychosocial functioning $[10,11]$.

Declining resources with advancing age make individuals increasingly vulnerable (e.g., [12]). Neighborhood characteristics might constitute a resource to draw from to maintain perceptions of control in older age [13]. For example, increasing (physical or social) loss experiences might make older adults more dependent on their immediate environment. Having access to neighborhood resources, such as public transportation or doctors, might affect how much control older adults perceive over their lives or how much control they feel others have over their lives. Similarly, low resource neighborhood settings (e.g.,

Control Beliefs and Neighborhood Characteristics high crime rates) might amplify existing vulnerabilities in older adults and therefore undermine how much control people perceive over their lives [14]. Features of the neighborhood environment, such as land use characteristics, noise, or pollution might also affect older adults' perceptions of control, since they cannot regulate these features. Moreover, the physical environment can affect how older individuals interact with their neighborhood and its resources. For example, urban green and blue spaces might encourage individuals to walk more frequently [15], while noise or pollution may have the opposite effect.

In the current study, we apply multiple regression models to data on control beliefs, obtained from participants of the Berlin Aging Study II (BASE-II; $N=507$ ) and address 2 sets of questions about the role of residential environments for individual control beliefs. First, we examine the role of multisource geo-referenced indicators of neighborhood for internal and external control beliefs and provide a quantification of the size of these effects over and above key sociodemographic individual difference characteristics. We hypothesize that geo-referenced indicators of neighborhood are associated with internal and external control beliefs. Second, we explore how neighborhood-level characteristics are related to between-person differences in perceptions of control while additionally accounting for interactions with potentially relevant physical health and characteristics of cognitive functioning. We hypothesize that neighborhood-level factors are associated with internal and external control beliefs over and above potentially relevant physical health and cognitive functioning characteristics. We explicitly choose to examine a number of neighborhood characteristics from multiple resources to examine the collective effect of neighborhood on perception of control. This explanatory approach allows us to gain first insights into the combined effect of neighborhood characteristics on perceptions of control, while accounting for cognitive, health, psychosocial, and sociodemographic factors.

\section{Materials and Methods}

\section{Participants and Study Design}

The Berlin Aging Study II is a multidisciplinary prospective cohort study of older individuals living in the Berlin metropolitan area $[16,17]$. The original sample consists of about 2,200 individuals divided into a "young" subsample (600 men and women aged $20-35$ years) and an "old" subsample (1,600 men and women aged 60-80 years). The data collection involved a medical anamnesis and examination at the Charité-Universitätsmedizin Berlin, a survey administered by the German Socio-Economic Panel Study (SOEP) group at DIW Berlin, and a cognitive and psychosocial as- 
sessment conducted at the Max Planck Institute for Human Development (see also $[16,17])$. Subjects gave their written informed consent and the study protocol was approved by the Ethics Committee of the Max Planck Institute for Human Development, Berlin, Germany, and Charité-Universitätsmedizin Berlin.

In the current study, we used data from 507 participants of the older age-group (60-80 years) and 119 participants from the younger age-group (20-35 years) of the socio-economic, psychosocial, and medical module of BASE-II who provided data on our variables of interest. Previous studies have identified associations between neighborhood characteristics and health outcomes in older adults using sample sizes of approximately 500 participants (for reviews, see [18]). Using a sample size of over 500 in the current study will allow us to identify any potential associations between our variables of interest.

The survey took place between September 2012 and January 2013. For a detailed description of the socioeconomic module, see [19]. Specifically, participants were asked to fill in an individual questionnaire concerning their biographical data, socioeconomic, and sociodemographic characteristics as well as a household questionnaire covering their living conditions and household information. Questionnaires and data collection procedures were adapted from the SOEP core survey, the largest multi-cohort survey in Germany.

For the psychosocial module, measures were obtained as part of a take-home questionnaire. The cognitive test used here as a correlate was administered as part of a comprehensive cognitive test battery and was carried out by trained interviewers in group sessions of 3-6 participants. Medical information was obtained at Charité-Universitätsmedizin Berlin through a 2-day protocol including a wide range of laboratory and functional tests as well as a comprehensive anamnesis performed by a physician [16].

\section{Measures}

Internal and External Control Beliefs

The 3 control belief dimensions were assessed using items derived from conceptual and empirical work on locus of control [2, 20]. For each dimension, participants were asked to indicate the extent to which they agreed with 3 or 4 statements, using a 5-point Likert-scale with end point labels of $1=$ "does not apply to me at all" and 5 = "applies very well to me." Following previous empirical work, we then used a sum score for each subscale [5]. Internal control beliefs were measured as the average response to 6 items (Cronbach's alpha $\geq 0.78$; e.g., "It's up to me to arrange for all the good things in my life"). External control beliefs in powerful others were measured as the average of 4 items (Cronbach's alpha $\geq 0.77$; e.g., "The good things in my life are determined by other people"). External control beliefs in chance were measured as the average of 4 items (Cronbach's alpha $\geq 0.70$; e.g., "The good things in my life are, for the most part, a matter of luck"). All subscales were moderately correlated, indicating the distinct nature of these facets as shown in previous research (e.g., [5]).

\section{Neighborhood Characteristics}

The geo-coordinates of the residential addresses of the BASE-II participants allowed us to combine the BASE-II data with georeferenced information on environmental and neighborhood characteristics from a wide range of sources, which capture the dimensions of access to neighborhood resources, neighborhood disadvantage, physical neighborhood environment, and neighborhood composition. These indicators were provided at different levels of aggregation, ranging from exact geocoded locations (e.g., for access to neighborhood resources) to broader areal units, such as urban planning areas or districts. It is important to acknowledge that the level of aggregation can influence the results of statistical analyses [21] (this is often referred to as the "modifiable areal unit problem"). Unfortunately, we cannot freely choose the level of aggregation for our analysis. Rather than aggregate all measures of neighborhood characteristics to the district level, we will use all indicators at the lowest possible level of aggregation.

Our measures of access to neighborhood resources are based on the distance to local amenities derived from OpenStreetMap. We calculated the exact distances to the closest hospitals, physicians, and public transport stops based on the residential addresses of the BASE-II participants.

Neighborhood disadvantage was assessed using 2 distinct measures: first, local unemployment rate, provided by the Statistical Office Berlin-Brandenburg for 447 small urban planning areas and second, district-level crime rates provided by the Berlin Police. We used the natural logarithm of the total number of crimes per 100,000 residents in 2012 .

The physical environment is represented through land use and air traffic. Land use in the neighborhood was assessed using the European Urban Atlas, provided by the European Environment Agency. Based on satellite imagery, the European Urban Atlas assigns urban areas $>0.25$ ha to well-defined land use categories, such as green urban areas (e.g., parks), forests, waters, and wasteland (e.g., former industrial areas) [22]. For this study, we used 4 variables (i.e., green spaces, forests, waters, and wasteland) measuring the square meters covered by each category in an area with a $1,000 \mathrm{~m}$ radius around each household [for further details see [1, 23]). Data on air traffic were provided by German Air Traffic Control (Deutsche Flugsicherung $\mathrm{GmbH}$ ) for all flights starting or landing at the airports Berlin Schönefeld and Berlin Tegel between May 1 and October 31, 2012. The data contain average, minimal, and maximal flight altitude as well as the total number of flights for a grid of 2,500 cells covering the whole Berlin area. We include data on air traffic as previous studies have shown that aircraft noise affects health (and in particular sleep quality) [24-26]. Moreover, in contrast to noise pollution through street traffic and industry, air traffic data are readily available for the whole metropolitan area. Finally, we include measures of the age structure ("share of children under 15 years" and "share of seniors over 65 years" in percent) for the 447 planning areas into our model to account for the neighborhood composition.

There was major variation in these neighborhood characteristics across the sample. For example, the local unemployment rate varied between 4 and 39\% with an average of 13\%. The share of children in the neighborhood varied between 5 and 23\% with a mean of $12 \%$, and the share of seniors varied between 2 and $38 \%$ (average of 17\%). Participants lived on average $190 \mathrm{~m}$ away from the closest public transport stop, $960 \mathrm{~m}$ from the nearest physician, and $3.7 \mathrm{~km}$ from the nearest hospital. There were on average 60 crimes per month and 100,000 residents. The average number of flights was 1,313 with a minimum altitude of $373 \mathrm{~m}$ and an average altitude of $2,028 \mathrm{~m}$. The land covered by urban green areas varied between 0 and 111 ha, while the area covered by forests varied between 0 and 250 ha. Wasteland made up between 0 and 7 ha, while water covered between 0 and 124 ha (see online suppl. Table SUM.1; see www.karger.com/doi/10.1159/000515634 for all online suppl. material for further details). 
Individual-Level Covariates

We also included several socio-demographic, physical health, and cognitive functioning measures in our analysis. Age was calculated based on year and month of the interview as well as year and month of birth. Gender was coded as women (0) and men (1). Education was measured in number of years $(\mathrm{M}=14.4, \mathrm{SD}=2.94$; range: 7-18). Income was assessed as net monthly household income, adjusted for household size (based on the OECD-equivalence scale), and transformed using the natural logarithm. Partnered was assessed as a binary variable with $1=$ cohabiting with a partner or $0=$ not cohabiting with a partner. Morbidity was assessed as part of the medical examinations by physicians at the Charité University Hospital, Berlin. Diagnoses were obtained through participant reports, with select diagnosis (e.g., diabetes mellitus) being verified by additional (blood laboratory) tests (for details, see [27]). Diagnoses were used to compute a morbidity index largely based on the categories of the Charlson Index [28]. Cognitive functioning was measured using the digit symbol substitution test (WAIS; [29]). The test consists of a code box with 9 digit-symbol pairs where each digit is paired with a corresponding symbol, and rows of double boxes with a digit in the top box and an empty lower box. Participants were asked to fill in as many corresponding symbols as possible in $90 \mathrm{~s}$. Scores indicate the number of correctly filled boxes, with penalty for wrong answers (score = correct - wrong).

\section{Statistical Analysis}

We used linear regression models to estimate the predictive effects of neighborhood characteristics for control beliefs. All standard errors were adjusted to account for potential correlation within neighborhoods at level of urban planning regions. We estimated 3 models for each outcome variable: First, we estimated the overall predictive effects of neighborhood characteristics using the full sample. Then, we estimated models for the young age-group and the older age-group separately. In the following, we focus on results for the older age-group only, and estimates for the younger age-group are reported in the online suppl. material (see online suppl. SUM.1, 4). In all models, we included control variables for sex, a quadratic age trend, since previous studies highlight the nonlinear age trajectory of control beliefs in older age [8], marital status, years of education, and log of equivalized net monthly household income, morbidity, and cognitive functioning. In a further analysis, we examined interactions with all variables that have been previously shown to moderate the association between control beliefs and its correlates [8]. First, we estimated separate regression models including interaction terms with age, gender, education, and morbidity one at a time. Then, we retained those interactions that proved significant at the $10 \%$ level and re-estimated the model including all significant interaction terms in the same regression.

Finally, we conducted several sensitivity analyses. First, we reestimated our model on a subsample of respondents that reported no residential move outside their district within the last 10 years to reduce concerns about self-selection of individuals into particular urban areas which may be correlated with the outcome. For example, higher internal control individuals might move to areas with more resources, which in turn increases their internal control beliefs even further. Second, we estimated the regression models using a reduced set of covariates, controlling only for age, gender, and education. Third, we re-estimated our model and included subjective perceptions of the neighborhood as additional covari-

Control Beliefs and Neighborhood

Characteristics ates (see online suppl. SUM.6), which were associated with differences in health and well-being in previous research [30]. All models were estimated in STATA 15 [31].

\section{Results}

\section{Intercorrelations}

Online suppl. Table SUM.2 reports intercorrelations for the variables under study. The largest intercorrelations were obtained for external control beliefs in chance with both objective and perceived neighborhood characteristics. For example, participants report more external control beliefs in chance the higher the unemployment rate of their living area is $(r=0.126)$, the larger the share of welfare recipients $(r=0.110)$, the more flights in the area $(r=0.100)$.

Importantly, correlations between measures of neighborhood characteristics are in the small to moderate range, indicating that these tap into different areas of a larger construct space. To illustrate, variables within the same category tend to exhibit higher intercorrelations (e.g., land use forest and land use water: $r=0.293$ ), whereas variables across category and source show generally smaller correlations (e.g., local crime rate and perceived problems with crime $r=0.160$, both $p$ 's $<0.05$ if not lower).

\section{The Role of Objective Neighborhood Characteristics for Perceptions of Control}

Figure 1 shows the estimated coefficients for associations between objective neighborhood characteristics and control beliefs. All coefficients are standardized, i.e., effect sizes are measured in standard deviations. All models were controlled for differences in age, gender, education, household income, partnership status, morbidity, and cognitive functioning (see also online suppl. Table SUM.3; online suppl. Fig. SUM.1).

None of the associations between internal control beliefs and neighborhood characteristics are statistically significant at conventional levels. Moreover, most of the effects are relatively small. The strongest association was found for the share of seniors in the neighborhood ( $\beta=$ $-0.101, p>0.1)$. In contrast, Figure 1 also shows several statistically significant associations between external control beliefs and neighborhood characteristics. Notably, higher unemployment rate is significantly associated with higher external control beliefs in chance $(\beta=0.148, p<$ $0.01)$. A higher share of wasteland is associated with lower external control beliefs in chance $(\beta=-0.085, p<0.05)$. 


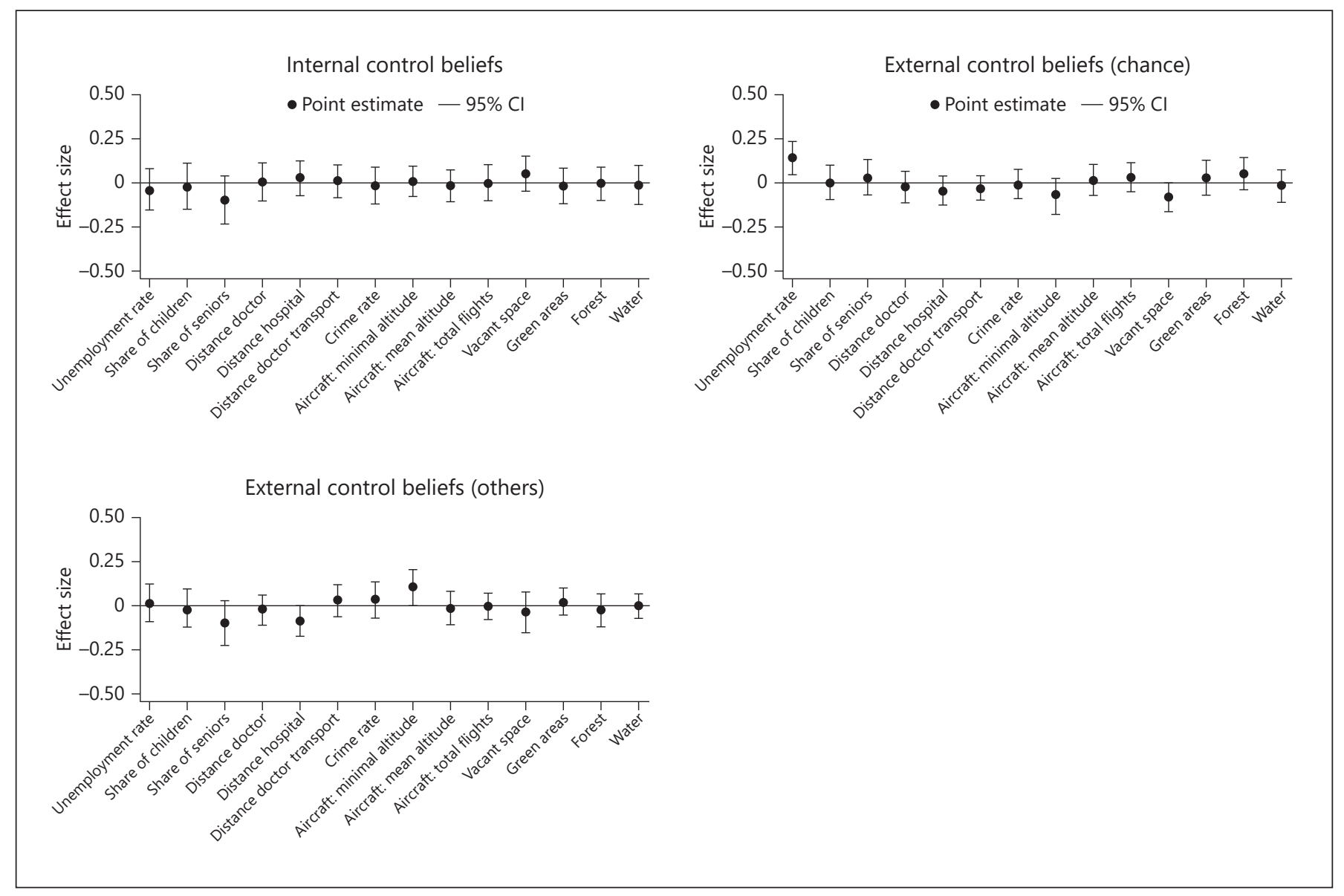

Fig. 1. Results from separate linear regression analyses on (standardized) control belief dimensions for the older sample. The dots mark the point estimates, the lines provide $95 \%$ confidence intervals. Regression analyses covaried for sex, a linear and quadratic age trend, marital status, years of education, log of equivalized net monthly household income, morbidity, and cognitive functioning. The results show that neighborhood composition was associated with internal and external control beliefs.

Individuals living further away from the nearest hospital report lower external control beliefs in powerful others $(\beta=-0.095, p<0.05)$, and a higher minimum altitude of aircrafts is associated with more external control beliefs in powerful others $(\beta=0.106, p<0.05)$.

Finally, we compared the $R^{2}$ from regression models controlling only for demographic characteristics (i.e., age, gender, and education) to a model which additionally includes our measures of neighborhood characteristics. For all 3 dimensions of control beliefs, the fraction of explained variance (as measured by the $R^{2}$ ) almost doubles (from $R^{2}=0.017$ to $R^{2}=0.030$ for internal control beliefs; $R^{2}=0.056$ to $R^{2}=0.102$ for external control beliefs in chance; $R^{2}=0.006$ to $R^{2}=0.030$ for external control beliefs in powerful others; see online suppl. Table SUM.3). In contrast, additionally controlling for household in- come, partnership status, morbidity, and cognitive functioning had a more limited impact on the $R^{2}$ for internal control beliefs and external control beliefs in chance, while the change in the $R^{2}$ was comparable to the inclusion of neighborhood characteristics for external control beliefs in powerful others. In other words, neighborhood characteristics are as important as known individual-level correlates.

The corresponding results for the younger sample are shown in the online suppl. material (see online suppl. Tables SUM.2, SUM.4). We find a positive association between the distance to the nearest hospital and internal control beliefs $(\beta=0.332, p<0.05)$. External control beliefs in chance are negatively associated with the minimum distance to GPs $(\beta=-0.329, p<0.05)$ and the average altitude of flights $(\beta=-0.236, p<0.05)$, and there is a 
Table 1. Standardized prediction effects $(\beta)$ from regression analyses of control beliefs by neighborhood characteristics and the correlates in older adults (full sample vs. nonmovers)

\begin{tabular}{|c|c|c|c|c|c|c|}
\hline & \multicolumn{2}{|c|}{ Internal control beliefs } & \multicolumn{2}{|c|}{ External control - chance } & \multicolumn{2}{|c|}{ External control - others } \\
\hline \multicolumn{7}{|l|}{ Individual covariates } \\
\hline Age & $-5.912(5.260)$ & $-3.217(5.765)$ & $4.676(4.699)$ & $3.626(4.644)$ & $-1.125(3.944)$ & $-0.876(4.300)$ \\
\hline $\mathrm{Age}^{2}$ & $4.213(3.744)$ & $2.354(4.113)$ & $-2.962(3.364)$ & $-2.209(3.301)$ & $0.945(2.764)$ & $0.678(3.018)$ \\
\hline Household income & $0.111(0.078)$ & $0.082(0.091)$ & $-0.166(0.080)^{*}$ & $-0.131(0.088)$ & $-0.162(0.062)^{* *}$ & $-0.111(0.073)$ \\
\hline Partnered & $-0.141(0.065)^{*}$ & $-0.144(0.071)^{*}$ & $0.001(0.050)$ & $-0.007(0.054)$ & $0.148(0.052)^{* *}$ & $0.128(0.059)^{*}$ \\
\hline Morbidity index & $-0.025(0.044)$ & $-0.029(0.050)$ & $-0.018(0.043)$ & $-0.018(0.047)$ & $-0.028(0.045)$ & $-0.052(0.046)$ \\
\hline Digit symbol test & $0.090(0.063)$ & $0.101(0.067)$ & $-0.062(0.056)$ & $-0.058(0.061)$ & $-0.093(0.058)$ & $-0.106(0.064)$ \\
\hline Constant & $0.931(0.802)$ & $0.512(0.873)$ & $-0.916(0.706)$ & $-0.766(0.709)$ & $0.015(0.624)$ & $0.039(0.679)$ \\
\hline Minimum distance: physician & $-0.005(0.056)$ & $-0.007(0.057)$ & $-0.029(0.047)$ & $-0.030(0.055)$ & $-0.025(0.045)$ & $-0.015(0.049)$ \\
\hline Minimum distance: hospital & $0.024(0.050)$ & $0.040(0.056)$ & $-0.055(0.043)$ & $-0.027(0.049)$ & $-0.096(0.042)^{*}$ & $-0.088(0.047)$ \\
\hline Minimum distance: public transport & $0.005(0.046)$ & $0.040(0.048)$ & $-0.036(0.038)$ & $-0.024(0.046)$ & $0.035(0.048)$ & $0.064(0.050)$ \\
\hline Crimes per 100,000 residents (log) & $-0.041(0.057)$ & $-0.041(0.064)$ & $-0.005(0.047)$ & $-0.005(0.053)$ & $0.032(0.054)$ & $0.018(0.061)$ \\
\hline Flights: minimum altitude & $0.003(0.046)$ & $-0.012(0.048)$ & $-0.062(0.048)$ & $-0.065(0.052)$ & $0.107(0.048)^{*}$ & $0.106(0.051)^{*}$ \\
\hline Flights: average altitude & $-0.015(0.049)$ & $-0.020(0.057)$ & $0.002(0.047)$ & $0.005(0.049)$ & $-0.019(0.049)$ & $-0.012(0.053)$ \\
\hline Flights: total number & $-0.052(0.034)$ & $-0.072(0.033)^{*}$ & $0.070(0.035)^{*}$ & $0.064(0.036)$ & $0.011(0.042)$ & $0.013(0.045)$ \\
\hline Area: wasteland & $0.064(0.054)$ & $0.021(0.062)$ & $-0.089(0.043)^{*}$ & $-0.094(0.046)^{*}$ & $-0.042(0.061)$ & $-0.020(0.067)$ \\
\hline Area: green space & $-0.017(0.054)$ & $-0.025(0.063)$ & $0.023(0.052)$ & $0.015(0.060)$ & $0.014(0.042)$ & $-0.022(0.047)$ \\
\hline Area: forest & $-0.003(0.053)$ & $-0.021(0.058)$ & $0.066(0.051)$ & $0.063(0.056)$ & $-0.053(0.049)$ & $-0.076(0.052)$ \\
\hline Area: water & $-0.005(0.061)$ & $-0.023(0.060)$ & $-0.024(0.048)$ & $-0.022(0.048)$ & $-0.006(0.036)$ & $0.004(0.038)$ \\
\hline$R^{2}$ & 0.044 & 0.043 & 0.104 & 0.089 & 0.064 & 0.059 \\
\hline
\end{tabular}

Estimates show standardized regression coefficients from a linear regression model. The "No move since 2002" sample only includes individuals who reported to live in the same district. ${ }^{*} p<0.05 ;{ }^{* *} p<0.01$.

positive association with the total number of flights $(\beta=$ $0.171, p<0.05$ ). Similarly, to the older sample, neighborhood characteristics contributed substantially to the explained variation in control beliefs.

\section{Heterogeneity by Age, Gender, Education, and Morbidity}

The interaction terms reveal considerable heterogeneity in the association between neighborhood and control beliefs, especially internal control beliefs (see online suppl. Table SUM.5). For example, while the estimate of the main effect suggests that larger vacancy is associated with higher internal control, the interactions show that this association diminishes with age and morbidity. In contrast, water areas show an increasingly stronger association with internal control for those with higher morbidity. Likewise, aircraft noise seems to be more strongly associated with internal control beliefs for those with higher education as well as men. Similarly, for external control beliefs in chance we find that the total number of flights seems to matter more for men and individuals with higher morbidity, whereas the average altitude of flights matters more for older individuals. Again, the pattern is relatively complex with some results pointing towards a positive association between aircraft noise and external control beliefs, while others point towards a negative relationship. For example, the interaction term with age suggests that for older individuals a higher average altitude of flights (i.e., less aircraft noise) is associated with higher external control beliefs. For external control be- 
liefs in powerful others, only 3 interaction terms were included in the model. None of them were statistically significant at the $5 \%$ level.

\section{Sensitivity Analyses}

We conducted several sensitivity analyses. First, we accounted for individual-level covariates of income, partnership status, morbidity, and cognitive functioning. Online suppl. Table SUM. 3 shows that most coefficient estimates are not affected by the inclusion of these covariates. Excluding these covariates from the model would result in 2 notable changes: In the reduced model, there is a significant association between forest areas and external control beliefs in chance $(\beta=-0.083, p<0.05)$, while the association between the minimal distance to the nearest hospital and external control beliefs in powerful others is no longer significant $(\beta=-0.026, p>0.1)$.

Second, we re-estimated our main model in Figure 1 for a subsample of older individuals who did not report a residential move outside their district in the last 10 years. Individuals select into their neighborhoods, and it appears plausible that those who are most affected by, for example, noise or crime might choose to move to a different neighborhood. This selection effect would attenuate our estimates. The results are shown in Table 1.

The "full sample" shows the estimates from our main model in Figure 1, while the column titled "No move since 2002 " excludes those individuals who reported a residential move between city districts between 2002 and 2012 . First, we note that very few individuals moved. This is in line with the previous findings suggesting that relocation rates in Germany are traditionally low [1]. Excluding movers only reduces the sample size by 58 observations. Moreover, the estimated associations are very similar across specifications, both qualitatively and quantitatively. Thus, we concluded that selection into neighborhood is unlikely to pose a major problem for our findings.

Finally, we estimated a model including subjective perceptions of the neighborhood as covariates. Our main results remained stable while controlling for subjective perceptions of neighborhood (see online suppl. Table SUM.6).

\section{Discussion}

This study examined associations between objectively measured neighborhood characteristics and 3 distinct dimensions of control beliefs for a sample of communitydwelling older individuals. For internal control, we found that the size and direction of these associations exhibited substantial heterogeneity across age, gender, education, and morbidity, which suggests that the role of neighborhood characteristics for perceptions of internal control differs considerably across individuals. For external control beliefs, we found that the unemployment rate is associated with higher external control beliefs in chance, whereas larger wasteland was associated with fewer beliefs in chance. The former association suggests that individuals in economically deprived areas feel more controlled by external circumstances. This is in line with work suggesting that contextual unemployment matters for health and well-being. The underlying idea has been described as the "collective burden of neighborhood unemployment" suggesting that neighborhood unemployment operates through mechanism such as labor or educational and market opportunities, deprivation in infrastructure, availability of healthy foods at affordable prices, increased stress, and lack of social support $[32,33]$. Our results are the first to suggest that this also holds true for perceptions of control. The latter association is more surprising. It is possible that a higher proportion of wasteland is indicative of neighborhoods that are located in areas with a large number of abandoned industrial sites and gaps between buildings and streets, which have not fully been (re)purposed. It could be that individuals perceive this as an opportunity window they could capitalize and benefit from but that is still beyond their own doing and thus feel less controlled by external circumstances.

We found that living closer to a hospital was associated with higher external control beliefs in powerful others. This could reflect that the presence of a hospital might serve as a frequent reminder of situations in which individuals depend on medical professionals. This could ultimately foster their belief of being controlled by external factors.

Finally, we also found that a higher minimal altitude of aircraft crossings is associated with higher external control beliefs in powerful others. This might seem counterintuitive because we would have expected that aircraft noise goes hand in hand with increased external control beliefs. However, our analysis of interaction effect shows that the association between aircraft noise and control beliefs is highly complex. For example, in the model for external control beliefs in chance the total number of flights (which should approximate more frequent aircraft noise) is associated with higher external control, but the average altitude (where higher values should represent lower noise levels) is also associated with higher external control. A potential explanation could be that our variables on flight crossings do not purely pick up the effects 
of aircraft noise, but are also driven by other dynamics, since flight paths also affect other characteristics of the neighborhood such as land prices. Furthermore, a previous study using the same data suggested that these objective indicators of aircraft noise are not associated with health and well-being, while the perceptions of aircraft noise are [30].

To our knowledge, no previous study had examined the relation between neighborhood characteristics and control beliefs. However, our findings are in line with previous research highlighting the importance of contextual characteristics for psychosocial functioning and specifically perceptions of control. For example, previous work highlighted how perceptions of control are shaped by one's immediate context (i.e., romantic relations [34]) and the socio-historical context (i.e., cohort differences [5]). Our findings extend this knowledge by showing that considering neighborhood contextual characteristics may also help us better understand the nature of control beliefs. This is consistent with earlier research on neighborhood and health that has found that (socioeconomic) deprivation is indeed associated with poor individual health (e.g., [35]). Our findings suggest that these associations generalize to key characteristics of psychosocial functioning. Interestingly, we did not find strong associations between green space and control beliefs, despite previous studies reporting significant associations with health and brain structure using the same data $[1,23]$. One possibility is that control beliefs and health are simply distinct concepts, so findings do not necessarily contradict each other.

We found generally stronger associations between neighborhood characteristics and external control indicating that the neighborhood does not necessarily provide resources which might decrease or increase internal control beliefs, but rather affects how people use their individual resources and thus exert external control. This is in line with previous research [5] indicating that external control beliefs are beliefs about personal constraints with certain outcomes being beyond one's personal control because external conditions (e.g., politics and neighborhood) determine relevant aspects of one's life.

\section{Study Limitations}

In closing, we acknowledge several limitations of our report. While the sample offers rich information on the individual participants in the study, the sample size is rather small, precluding us from drawing reliable comparisons between younger and older individuals. In our sensitivity analysis, our sample was even smaller due to missingness on control variables. In order to ensure that all models were based on the same data, we re-ran all models using the smaller samples. Results remained stable indicating that differences where not driven by differences in sample size.

Second, the BASE-II sample is positively selected. Selectivity analyses indicate that BASE-II participants were on average better educated, healthier, and reported higher well-being. We would thus expect that the neighborhood effects in the whole population are even more pronounced because the literature typically reports larger effects for individuals from disadvantaged backgrounds [36]. Similarly, data were not representative for the whole of Germany, but only drawn from the Berlin metropoli$\tan$ area. Berlin is not a mega-city (population of $3,556,792$ ), but geographically large (approximately $344.35 \mathrm{sqmi}$ ) and therefore diverse in terms of neighborhood composition. Future studies should aim to replicate our findings using data from other geographical contexts. In particular, a comparison of rural versus urban areas would be highly interesting for future research. It is not only likely that some characteristics of the neighborhood environment are more salient in rural than in urban areas (such as distances to healthcare providers) and vice versa, but also the shape and size of a person's perceived neighborhood will likely differ.

While we were able to examine a wide range of neighborhood characteristics, these characteristics were unfortunately not measured at the same spatial resolution. Instead, some characteristics (e.g., the crime rate) were measured at the district-level (12 units) and therefore show little variation, while others were measured at the level of urban planning regions (447 units), air traffic grids (2,500 units), or even the residential addresses. Individuals' perceptions of their local neighborhood might differ from these administrative units, and as such it is possible that the neighborhood affects control beliefs at a different spatial scale or level of aggregation than those used in this study, which might also explain differences in the estimated effects of subjective and objective neighborhood characteristics [30]. We also did not consider spatial dependencies between neighborhoods (e.g., unemployment in areas around the participants neighborhood). Future studies should therefore further examine spatial spillover effects and issues such as modifiable areal units and uncertain geographic context problem [37].

We cannot draw conclusions about causality using cross-sectional data. Individuals who perceive little control or who feel controlled by external forces might select themselves into poorer neighborhoods. We tried to address these concerns by using objective neighborhood in- 
formation and at the same performing sensitivity analysis controlling for moves. However, only natural experiments would allow to further move towards establishing causality. If such data would become available, questions of causality should be addressed.

\section{Implications}

The present study examined associations between perceptions of control and a wide range of objective neighborhood characteristics using data from the Berlin Aging Study II. Results indicate that higher unemployment was associated with more external control beliefs in chance, while larger wasteland areas were associated with lower beliefs in chance. Including neighborhood characteristics in part doubled the amount of explained variance compared with models that covaried for demographic characteristics only. We conclude that over and above cognitive, physical health, and psychosocial factors neighborhood access to resources are crucial for control beliefs. Our findings can inform interventions to build up neighborhood social capital which might be especially necessary in residential areas with high unemployment.

\section{Acknowledgements}

This work reports data from the BASE-II project, which was supported by the German Federal Ministry of Education and Research (Bundesministerium für Bildung und Forschung, BMBF) under Grant Nos. \#01UW0808; \#16SV5536K, \#16SV5537, \#16SV5538, \#16SV5837; \#01GL1716A; and \#01GL1716B). Another source of funding is the Max Planck Institute for Human Development, Berlin, Germany. Additional contributions (e.g., equipment, logistics, and personnel) are made from each of the other participating sites. Further details about the study can be obtained at www.base2.mpg.de.

\section{Statement of Ethics}

The research was conducted ethically in accordance with the declaration of Helsinki. Subjects gave their written informed consent and that the study protocol was approved by the Ethics Committee of the Max Planck Institute for Human Development, Berlin, Germany, and Charité-Universitätsmedizin Berlin (January 12, 2011).

\section{Conflict of Interest Statement}

The authors have no conflicts of interest to declare.

\section{Funding Sources}

This work reports data from the BASE-II project, which was supported by the German Federal Ministry of Education and Research (Bundesministerium für Bildung und Forschung, BMBF) under Grant Nos. \#01UW0808; \#16SV5536K, \#16SV5537, \#16SV5538, \#16SV5837; \#01GL1716A; and \#01GL1716B). Another source of funding is the Max Planck Institute for Human Development, Berlin, Germany.

\section{Author Contributions}

Design of the work: J.D., P.E., C.K., and J.K. Data acquisition: J.D., P.E., S.D., J.G., I.D., U.L., G.G.W., D.G., and S.K. Data analysis: J.D. and P.E. Writing of paper: J.D. and P.E. All authors critically and substantively revised the manuscript.

\section{Data Availability Statement}

The data can be requested from the steering committee of the Berlin Aging Study II. Further details about the procedure can be obtained at www.base2.mpg.de.

\section{References}

1 Krekel C, Kolbe J, Wüstemann H. The greener, the happier? The effect of urban land use on residential well-being. Ecol Econ. 2016 Jan;121:117-27.

2 Levenson H. Differentiating among internality, powerful others, and chance. In: Lefcourt HM, editor. Research with the locus of control construct. New York: Academic Press; 1981. Vol. 1; p. 15-63.

3 Reich JW, Infurna FJ. Perceived control: theory, research, and practice in the first 50 years. New York: Oxford University Press; 2016.

4 Lachman ME, Weaver SL. Sociodemographic variations in the sense of control by domain: findings from the MacArthur studies of midlife. Psychol Aging. 1998 Dec;13(4):55362.
5 Gerstorf D, Drewelies J, Duezel S, Smith J, Wahl H, Schilling OK, et al. Cohort differences in adult-life trajectories of internal and external control beliefs: a tale of more and better maintained internal control and fewer external constraints. Psychol Aging. 2019 Dec; 34(8):1090-108.

6 Bandura A. Self-efficacy: the exercise of control. New York: Freeman; 1997.

7 Lachman ME. Perceived control over agingrelated declines. Curr Dir Psychol Sci. 2006 Dec;15(6):282-6.

8 Drewelies J, Wagner J, Tesch-Römer C, Heckhausen J, Gerstorf D. Perceived control across the second half of life: the role of physical health and social integration. Psychol Aging. 2017;32(1):76-92.
9 Infurna FJ, Gerstorf D, Ram N, Schupp J, Wagner GG. Long-term antecedents and outcomes of perceived control. Psychol Aging. 2011;26(3):559-75.

10 Bronfenbrenner U. Ecology of the family as a context for human development: research perspectives. Dev Psychol. 1986 Nov;22(6): 723-42.

11 Sampson RJ, Morenoff JD, Gannon-Rowley T. Assessing "neighborhood effects": social processes and new directions in research. Annu Rev Sociol. 2002 Aug;28(1): 443-78.

12 Baltes PB. Theoretical propositions of lifespan developmental psychology: on the dynamics between growth and decline. Dev Psychol. 1987;23(5):611-26. 
13 Wahl H, Gerstorf D. A conceptual framework for studying ntext ynamics in ging (CODA). Dev Rev. 2018 Dec;50:155-76.

14 Glass TA, McAtee MJ. Behavioral science at the crossroads in public health: extending horizons, envisioning the future. Soc Sci Med. 2006 Apr;62(7):1650-71.

15 Owen N, Cerin E, Leslie E, duToit L, Coffee N, Frank LD, et al. Neighborhood walkability and the walking behavior of Australian adults. Am J Prev Med. 2007 Nov;33(5):387-95.

16 Bertram L, Böckenhoff A, Demuth I, Düzel S, Eckardt R, Li S, et al. Cohort profile: the Berlin Aging Study II (BASE-II). Int J Epidemiol. 2014 Jun;43(3):703-12.

17 Gerstorf D, Bertram L, Lindenberger U, Pawelec G, Demuth I, Steinhagen-Thiessen E, et al. Editorial. Gerontology. 2016;62(3):311-

18 Cerin E, Nathan A, van Cauwenberg J, Barnett DW, Barnett A. The neighbourhood physical environment and active travel in older adults: a systematic review and meta-analysis. Int J Behav Nutr Phys Act. 2017 Feb 6; 14(1):15.

19 Böckenhoff A, Sassenroth D, Kroh M, Siedler T, Eibich P, Wagner GG. The Socio-Economic Module of the Berlin Aging Study II (SOEPBASE): description, structure, and questionnaire. SSRN J.

20 Kunzmann U, Little T, Smith J. Perceiving control: a double-edged sword in old age. J Gerontol B Psychol Sci Soc Sci. 2002 Nov 1; 57(6):P484-91.

21 Ebert T, Gebauer JE, Brenner T, Bleidorn W, Gosling SD, Potter J, et al. Are regional differences in personality and their correlates robust? Applying spatial analysis techniques to examine regional variation in personality across the U.S. and Germany. Working Papers on Innovation and Space 2019-05 Philipps University Marburg, Department of Geography.

22 European Environment Agency. Copenhagen, Denmark: 2011

23 Kühn S, Düzel S, Eibich P, Krekel C, Wüstemann $\mathrm{H}$, Kolbe J, et al. In search of features that constitute an "enriched environment" in humans: associations between geographical properties and brain structure. Sci Rep. 2017 Dec;7(1):11920.

24 Bronzaft AL. Noise pollution: a hazard to physical and mental well-being. In: Bechtel RB, Churchmann A, editors. Handbook of environmental psychology. John Wiley \& Sons Inc.; 2002. p. 499-510.

25 Boes S, Nüesch S, Stillman S. Aircraft noise, health, and residential sorting: evidence from two quasi-experiments. Health Econ. 2013 Sep;22(9):1037-51.

26 Eibich P, Kholodilin K, KrekelWagner CGG. Aircraft noise in Berlin affects quality of life even outside the airport grounds. DIW Econ Bull. 2015;5(9): 127-33

27 Meyer A, Salewsky B, Buchmann N, Steinhagen-Thiessen E, Demuth I. Relative leukocyte telomere length, hematological parameters and anemia: data from the Berlin Aging Study II (BASE-II). Gerontology. 2016;62(3): 330-6.

28 Charlson M, Pompei P, Ales K, MacKenzie C. A new method of classifying prognostic comorbidity in longitudinal studies: development and validation. J Chronic Dis. 1987; 40(5):373-83.

29 Wechsler D. Manual for the Wechsler adult intelligence scale. New York: Psychological Corporation; 1955.
30 Eibich P, Krekel C, Demuth I, Wagner GG Associations between neighborhood characteristics, well-being and health vary over the life course. Gerontology. 2016;62(3):362-70.

31 StataCorp. Stata statistical software: release 15. College Station, TX: StataCorp LLC; 2017.

32 Brydsten A, Gustafsson PE, Hammarström A, San Sebastian M. Does contextual unemployment matter for health status across the life course? A longitudinal multilevel study exploring the link between neighbourhood unemployment and functional somatic symptoms. Health Place. 2017 Jan;43:113-20.

33 Pickett KE. Multilevel analyses of neighbourhood socioeconomic context and health outcomes: a critical review. J Epidemiol Community Health. 2001 Feb 1;55(2):111-22.

34 Drewelies J, Chopik WJ, Hoppmann CA, Smith J, Gerstorf D. Linked lives: dyadic associations of mastery beliefs with health (behavior) and health (behavior) change among older partners. J Gerontol B Psychol Sci Soc Sci. 2018 Jun 14;73(5):787-98.

35 Stafford M, Marmot M. Neighbourhood deprivation and health: does it affect us all equally? Int J Epidemiol. 2003 Jun;32(3):35766.

36 Cagney KA, Glass TA, Skarupski KA, Barnes LL, Schwartz BS, Mendes de Leon CF. Neighborhood-level cohesion and disorder: measurement and validation in two older adult urban populations. J Gerontol B Psychol Sci Soc Sci. 2009 May 1;64B(3):415-24.

37 Arcaya MC, Tucker-Seeley RD, Kim R, Schnake-Mahl A, So M, Subramanian S. Research on neighborhood effects on health in the United States: a systematic review of study characteristics. Soc Sci Med. 2016 Nov; 168: 16-29. 